\title{
Investigation of Ammonia-sensing Mechanism on Polypyrrole Gas Sensor Based on Experimental and Theoretical Evidence
}

\author{
Zhaorui Zhang, ${ }^{1}$ Haiying Du, ${ }^{1 *}$ Wencai $\mathrm{Yi}_{1}{ }^{2 * *}$ Yanhui Sun, ${ }^{3}$ \\ Yangong Zheng, ${ }^{4}$ Yuxia $\mathrm{Wu},{ }^{1}$ Shupeng Sun, ${ }^{4}$ and Shuaikang $\mathrm{Xu}^{1}$ \\ ${ }^{1}$ College of Mechanical and Electronic Engineering, Dalian Minzu University, Dalian 116600, China \\ ${ }^{2}$ Laboratory of High Pressure Physics and Material Science, School of Physics and Physical Engineering, \\ Qufu Normal University, Qufu 273165, China \\ ${ }^{3}$ College of Information and Communication Engineering, Dalian Minzu University, Dalian 116600, China \\ ${ }^{4}$ Faculty of Information Science and Engineer, Ningbo University, Ningbo 315020, China
}

(Received February 12, 2021; accepted April 2, 2021)

Keywords: ammonia-sensing properties, gas-sensing mechanism, selectivity, density functional theory

Ammonia is an air pollutant and the understanding of the ammonia-sensing mechanism is valuable for developing new gas sensors. In this study, polypyrrole (PPy) nanosheets were synthesized by low-temperature oxidation polymerization in a water bath at $0{ }^{\circ} \mathrm{C}$. An ammonia sensor based on the PPy nanosheets was prepared and tested with an ammonia concentration range of 2-500 ppm. The tested results demonstrate that the PPy sensor exhibited excellent ammonia sensitivity and selectivity at room temperature (RT). The sensitivity to ammonia was 1.029 at $2 \mathrm{ppm}$ and 2.153 at $500 \mathrm{ppm}$. The adsorption behaviors of PPy to different analytes (ammonia, acetone, formaldehyde, and benzene) were simulated and investigated by density functional theory (DFT). The calculated results show that the adsorption energy of ammonia was $0.433|\mathrm{eV}|$, which is much larger than that of the other analytes. Furthermore, the charge transfer and the changes in the bond length and angle were carefully compared between different adsorption systems. The calculation results were consistent with our experimental evidence, which demonstrated that the PPy sensor has the highest adsorption capacity for ammonia among the four analytes. The ammonia-sensing mechanism on the PPy sensor was proved from the calculation results obtained by DFT and will support the development of new advanced gas sensors.

\section{Introduction}

Ammonia is a harmful gas and environmental pollutant, ${ }^{(1,2)}$ and the atmospheric concentration of ammonia is gradually increasing due to a wide range of human activities, which include agriculture and the manufacturing of electronics and chemicals. ${ }^{(3,4)}$ The lower limit of human olfactory perception of ammonia is about $50 \mathrm{ppm}$, and the respiratory system, eyes, and skin are damaged when the ammonia concentration is over $500 \mathrm{ppm} .{ }^{(5-7)}$ Therefore, ammonia detection has been an active research topic and has attracted many researchers. ${ }^{\left({ }^{(8)}\right)}$ It is important

*Corresponding author: e-mail: duhaiying@dlnu.edu.cn

** Corresponding author: e-mail: yiwc@qfnu.edu.cn

https://doi.org/10.18494/SAM.2021.3330 
to develop a high-sensitivity and low-cost ammonia sensor. Also, the investigation of the ammonia-sensing mechanism by experiment and theory could accelerate this process.

Many different types of ammonia sensors have been developed, including those based on metal oxides, ${ }^{(10)}$ catalysts, ${ }^{(11,12)}$ and conducting polymers. ${ }^{(13-15)}$ The conducting polymer sensors are widely used in the energy storage, ${ }^{(16)}$ electrocatalysis, ${ }^{(17)}$ electrorheology, ${ }^{(18)}$ biomedicine, ${ }^{(19)}$ and ammonia-monitoring fields because of their low ionization potentials, low-energy optical transitions, high conductivities, room temperature (RT) operation, and high electron affinities. ${ }^{(20,21)}$ Among the conducting polymer sensors, polypyrrole (PPy) sensors have been extensively investigated for ammonia measurement due to their adjustable conductivity, easy fabrication, and low cost. ${ }^{(22)}$ In 1997, Penza et al. developed a PPy thin film by the Langmuir-Blodgett technique, which exhibited excellent ammonia-sensing properties. ${ }^{(23)} \mathrm{Kim}$ and Yoo developed a PPy sensor for monitoring low concentrations of ammonia.(24) Aditeejoshi et al. explored the high selectivity of PPy films for ammonia gas at RT. ${ }^{(25)}$ However, there is still insufficient direct and consistent evidence from both experiment and theoretical calculations to clarify the mechanism of ammonia sensing on a PPy nanosheet.

In this study, PPy nanosheets were synthesized by low-temperature oxidation polymerization, and a gas sensor based on the nanosheets was fabricated to detect ammonia at RT. Then the ammonia-sensing properties on the PPy sensor were explored. The sensitivity and selectivity of the PPy sensor were measured and analyzed for four different analytes (ammonia, acetone, formaldehyde, and benzene) using a dynamic testing system. The adsorption behavior of PPy for different analytes was simulated using density functional theory (DFT). The performance parameters of the PPy adsorption analytes, including bond lengths, bond angles, adsorption energies, and charge transfer, were calculated and used to clarify the ammonia-sensing mechanism.

\section{Experiment and Characteristics}

\subsection{Preparation of PPy}

Pyrrole and ferrous chloride hexahydrate were purchased from Sigma-Aldrich, U.S., and Sinopharm Chemical Reagent Co., Ltd., China, respectively. All chemical reagents were used without further purification. PPy was prepared by low-temperature oxidation polymerization. $1.4 \mathrm{~mL}$ of pyrrole $(0.971 \mathrm{~g} / \mathrm{mL})$ solution was added to $25 \mathrm{~mL}$ of deionized water and was dispersed by ultrasound for $30 \mathrm{~min}$ to ensure a uniform dispersion. $1 \mathrm{~mol} / \mathrm{L}$ ferrous chloride hexahydrate solution was dripped slowly into the pyrrole suspension in a $0{ }^{\circ} \mathrm{C}$ ice bath. Black PPy was obtained after $8 \mathrm{~h}$ under vigorous magnetic stirring, filtration, cleaning, and drying.

\subsection{Material characterization}

The structure of the PPy samples was characterized using an X-ray diffractometer with the radiation intensity of $\mathrm{Cu} \mathrm{K \alpha 1}\left(\mathrm{D} / \mathrm{Max} 2400\right.$, Rigaku, Japan) and a step length of $0.02^{\circ}$ in the $2 \theta$ region of $25-80^{\circ}$. The surface morphology was observed by field-emission scanning electron microscopy (FE-SEM, Hitachi S-4800, Japan). FT-IR absorption spectroscopy and Raman 
spectroscopy were carried out using an FT-IR spectrometer (Tensor80V, Bruker Optics, Germany) and a Raman spectrometer (Renishaw In Via Raman Microscope, U.K.), respectively.

\subsection{Preparation of sensor}

The prepared PPy powder was wetted with deionized water to form a slurry. The slurry was coated on a silicon substrate, which was $4 \times 6 \mathrm{~mm}^{2}$ in size with a pair of Pt electrodes $20 \mu \mathrm{m}$ in width. The preparation process of the PPy sensor is shown in Fig. 1. The gas-sensing characteristics of the PPy sensor were tested using a dynamic testing system. The response degree of the sensor was determined as $S=R_{g} / R_{a}$, ${ }^{(26)}$ where $S$ is the response of the PPy sensor, $R_{a}$ is the stable resistance of the sensor in the air, and $R_{g}$ is that of the target gas.

\subsection{Computational methods}

The sensing mechanism was further investigated by first-principles calculations, and the interactions of ammonia, formaldehyde, acetone, and benzene on the PPy sensor were analyzed. The adsorption models of the PPy sensor and the above gases were constructed and then were optimized by DFT, as implemented in the Vienna Ab-initio Simulation Package (VASP) ${ }^{(27)}$ with the generalized gradient approximation (GGA) of Perdew, Burke, and Ernzerhof (PBE). ${ }^{(28)}$ The cutoff energy was set as $400 \mathrm{eV}$ and k-point sampling with a mesh of $2 \times 2 \times 1$ in the Brillouin zone (BZ) was performed. A vacuum layer of $10 \AA$ was added to remove the interactions between neighbor slabs, and the optB88-vdW functional was used to evaluate the van der Waals interactions. ${ }^{(29)}$ The adsorption energy $\left(E_{a d s}\right)$ was defined as follows: ${ }^{(30)}$

$$
E_{a d s}=E_{P P y+X}-E_{P P y}-E_{X},
$$

where $E_{a d s}$ denotes the adsorption energy and $E_{P P y+X}, E_{P P y}$, and $E_{X}$ are the total energy of the adsorption system, the system energy of PPy, and the energy of the gas, respectively. Electron transfer was calculated by Bader's quantum theory of atoms in molecules (QTAIM). ${ }^{(31)}$ The qvasp functional was used to postprocess VASP-calculated raw output files. ${ }^{(32)}$
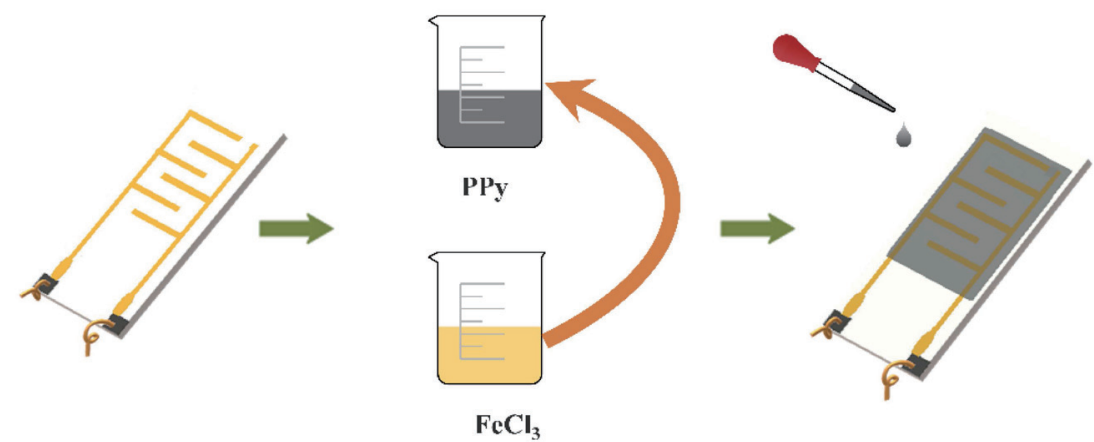

Fig. 1. (Color online) Preparation process of the PPy sensor. 


\section{Results and Discussion}

\subsection{Analysis of characterization}

The surface morphology of the PPy nanopowder was characterized through scanning electron microscopy (SEM), and SEM images of the PPy nanosheets are shown in Figs. 2(a) and 2(b). As can be seen from the images, the PPy nanoparticles that aggregated on the silicon substrate had a nanosheet structure with a size of about $100 \mathrm{~nm}$, which looked like flower petals.

The structural properties of the PPy nanosheets as-prepared using low-temperature oxidation polymerization were characterized by X-ray diffraction (XRD), Raman spectroscopy, and FT-IR spectroscopy. As shown in the XRD pattern in Fig. 3(a), there is a broad peak in the region of $15-30^{\circ}$, which suggested an amorphous structure, indicating that the short-range chain arrangement dominated, as has been observed for other PPy powders synthesized electrochemically. ${ }^{(33)}$ The Raman spectrum of the PPy nanosheets is shown in Fig. 3(b). The peak assigned at $1349 \mathrm{~cm}^{-1}$ was associated with the antisymmetrical $\mathrm{C}-\mathrm{N}$ stretching. The $\mathrm{C}=\mathrm{C}$
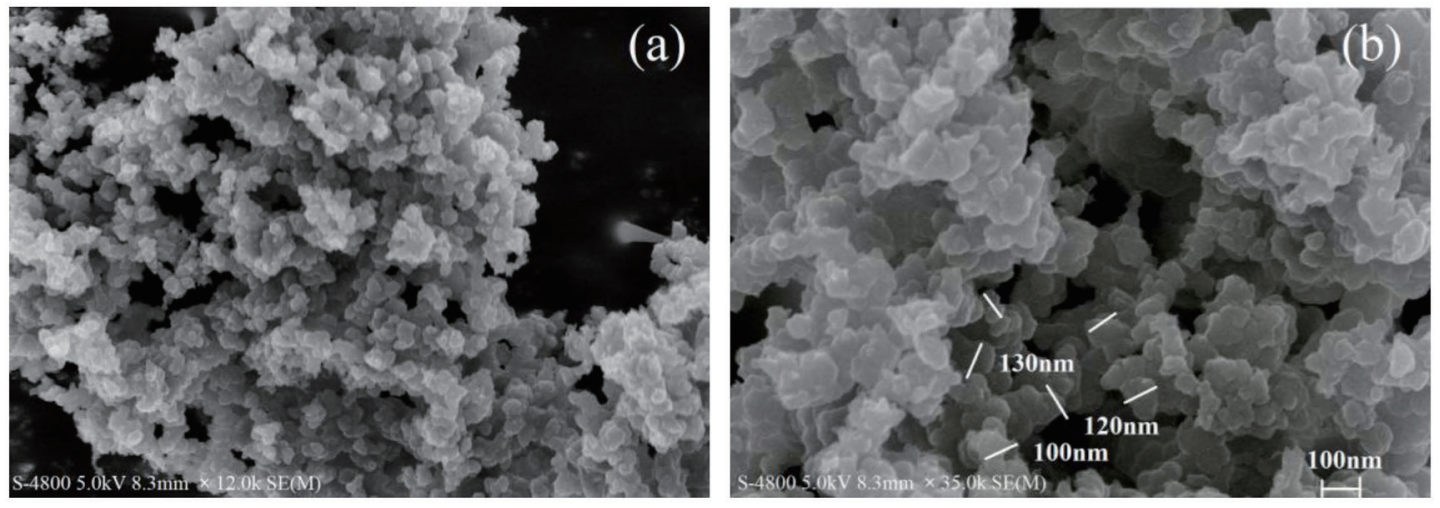

Fig. 2. SEM images of (a) PPy nanosheets at $8.3 \mathrm{~mm} \times 12.0 \mathrm{k}$ and (b) PPy nanosheets at $8.3 \mathrm{~mm} \times 35.0 \mathrm{k}$.

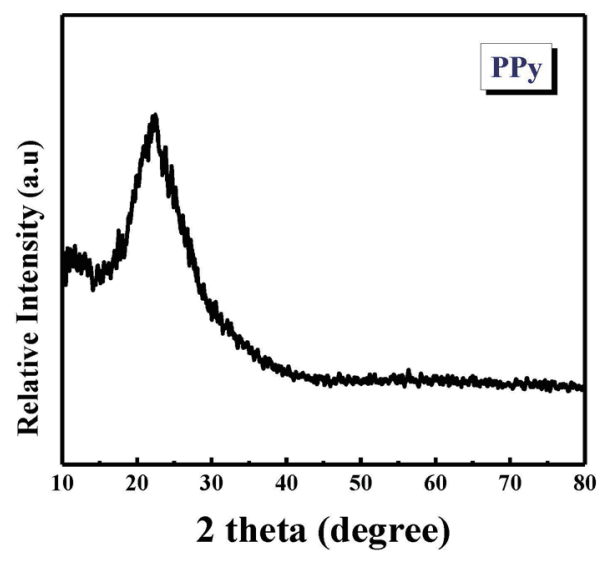

(a)

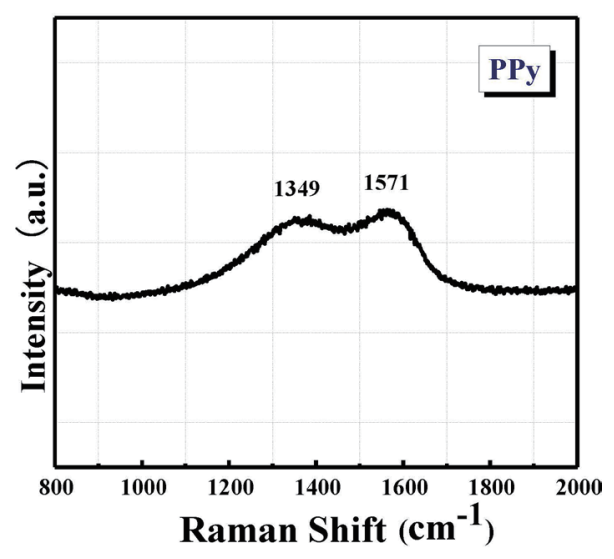

(b)

Fig. 3. (a) XRD pattern of the PPy nanosheets and (b) Raman spectrum of the PPy nanosheets. 
backbone stretching peak of PPy was responsible for the band at $1571 \mathrm{~cm}^{-1}$. This suggested that the black PPy may be composed of short-range pyrrole during synthesis. ${ }^{(34)}$

\subsection{Sensing properties of the PPy sensor}

The ammonia-sensing properties of the PPy sensor were examined over the concentration range of 2-500 ppm at RT and 40\% RH. Ten response cycles of the PPy sensor with the changes in the ammonia concentration are shown in Fig. 4(a). With increasing ammonia concentration, the sensitivity of the PPy sensor increased linearly. The sensitivity was 1.029 at the lowest concentration of $2 \mathrm{ppm}$ and 2.153 at $500 \mathrm{ppm}$. The response and recovery times of the PPy sensor for 100 ppm ammonia can be seen in Fig. 4(b) to be 87 and $132 \mathrm{~s}$ at RT, respectively. The response and recovery times of a gas sensor are defined as the times at which $90 \%$ of the final value is reached.

To clarify the interaction between ammonia and the PPy sensor, we further examined the FTIR spectra of the PPy nanosheets with adsorbed ammonia (Fig. 5). The peak at $3438 \mathrm{~cm}^{-1}$ is attributed to $\mathrm{N}-\mathrm{H}$ stretch vibration and the peak at $1637 \mathrm{~cm}^{-1}$ is attributed to the typical stretch vibration of PPy. ${ }^{(35)}$ The sharp peaks centered at 1384 and $1077 \mathrm{~cm}^{-1}$ are assigned to typical $\mathrm{C}-\mathrm{H}$ stretch vibration and $\mathrm{C}-\mathrm{H}$ deformation vibration of $\mathrm{PPy}{ }^{(36,37)}$ The band of the $\mathrm{C}=\mathrm{C}$ out-ofplane ring deformation vibration is at $954 \mathrm{~cm}^{-1}$. (38) The sharp peaks caused by $\mathrm{C}-\mathrm{C}$ ring stretching are concentrated at $1265 \mathrm{~cm}^{-1}$. The intensity of the $\mathrm{N}-\mathrm{H}$ stretch vibration peak near $3325 \mathrm{~cm}^{-1}$ increased with the concentration of ammonia. ${ }^{(39)}$ There was also an obvious increase in the $\mathrm{C}-\mathrm{H}$ and $\mathrm{C}-\mathrm{C}$ stretch vibration peaks with the ammonia concentration. This was caused by the significant changes in the bond lengths of the $\mathrm{C}-\mathrm{H}$ and $\mathrm{C}-\mathrm{C}$ rings and the dihedral angle of the PPy ring after the adsorption of ammonia. There is no sharp peak at $954 \mathrm{~cm}^{-1}$ in the FT-IR spectra of the PPy nanosheets with adsorbed ammonia; hence, the structural skeleton of PPy did not significantly change after the adsorption of ammonia. All the evidence demonstrates that the structure of PPy was perturbed by ammonia molecules, inducing the gas-sensing signal.

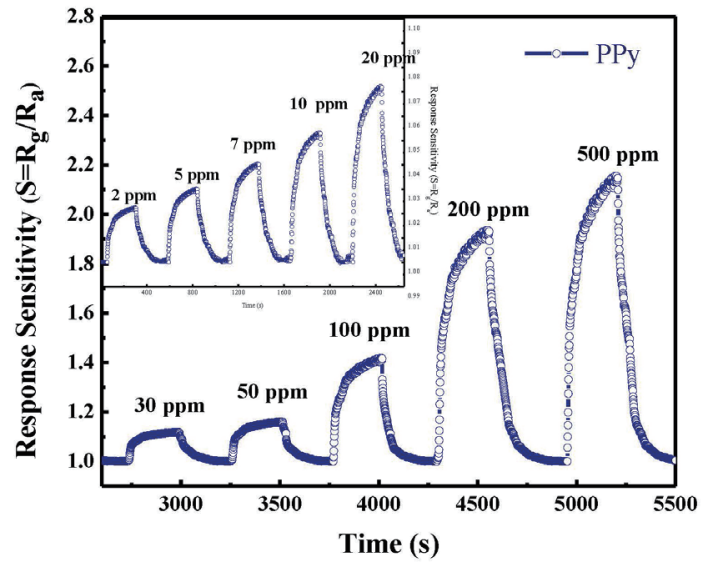

(a)

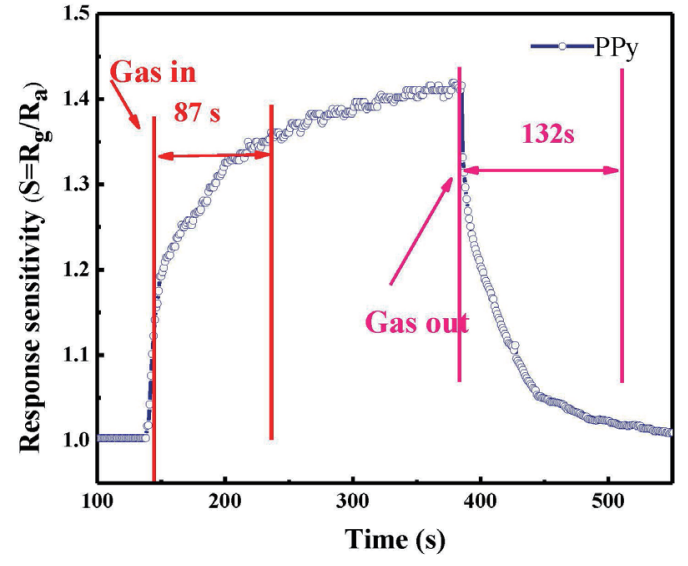

(b)

Fig. 4. (Color online) (a) Transient response curves of the PPy sensor for ammonia at concentrations of 2-500 ppm at RT. (b) Response and recovery times of the PPy sensor for 100 ppm ammonia. 


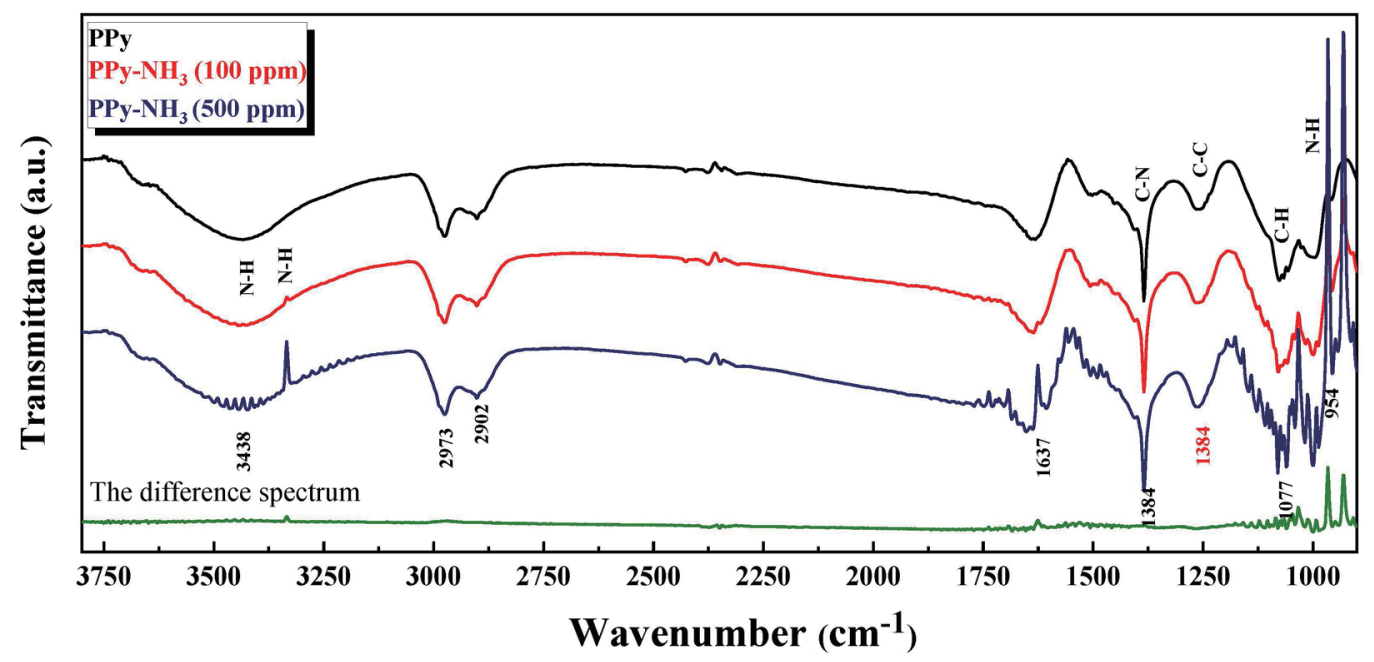

Fig. 5. (Color online) FT-IR spectra of PPy nanosheet without adsorbed ammonia and PPy nanosheets with adsorbed ammonia at concentrations of 100 and $500 \mathrm{ppm}$.

Selectivity is another important factor for gas sensors. The cross-responses of the PPy sensor to ammonia, acetone, formaldehyde, and benzene with a concentration of $100 \mathrm{ppm}$ are shown in Fig. 6(a). The response sensitivities of the PPy sensor to ammonia, acetone, formaldehyde, and benzene are 1.418, 1.017, 1.023, and 1.021 at $100 \mathrm{ppm}$, respectively, with almost no response to acetone, formaldehyde, and benzene. This indicated that pyrrole molecules interacted more strongly with ammonia molecules than with the other analytes. The long-term stability of the PPy sensor was measured at RT and is shown in Fig. 6(b). It can be seen that the PPy sensor maintained almost the same response over three months.

\subsection{Simulation analysis}

To clarify the high sensitivity and selectivity of the PPy sensor to ammonia, a first-principles calculation was performed to reveal the sensing micromechanism. The first challenge is that PPy has an amorphous structure (as indicated by its XRD patterns). Therefore, as shown in Table 1, we built a series of $n \mathrm{PPy}$ ( $n$ stands for the number of $\mathrm{C}_{4} \mathrm{NH}_{3}$ units) structure modes and used them to interact with ammonia. The adsorption energies were $0.433|\mathrm{eV}|\left(3 \mathrm{PPy}-\mathrm{NH}_{3}\right), 0.439|\mathrm{eV}|$ $\left(4 \mathrm{PPy}-\mathrm{NH}_{3}\right), 0.444|\mathrm{eV}|\left(5 \mathrm{PPy}-\mathrm{NH}_{3}\right), 0.448|\mathrm{eV}|\left(6 \mathrm{PPy}-\mathrm{NH}_{3}\right), 0.453|\mathrm{eV}|\left(7 \mathrm{PPy}-\mathrm{NH}_{3}\right)$, and $0.479|\mathrm{eV}|\left(\mathrm{nPPy}-\mathrm{NH}_{3}\right)$, with no significant difference among different modes; hence, we concluded that the length of the oligomers did not play a crucial role in the adsorption of ammonia, which is consistent with previous reports. ${ }^{(40)}$ Based on the characterization of the Raman spectrum, the PPy nanosheets were mainly composed of short-range oligomers. Therefore, 3PPy was chosen to reduce the computation time, and this structure was allowed to relax to its minimum energy. Furthermore, the moderate adsorption energy between PPy and $\mathrm{NH}_{3}$ was mainly attributed to a strong hydrogen bond between $\mathrm{H}$ and $\mathrm{N}$ atoms, and the change in the adsorption energy ranged from 0.43 to $0.47 \mathrm{eV}$, which is consistent with our FT-IR spectra. ${ }^{(40)}$ 


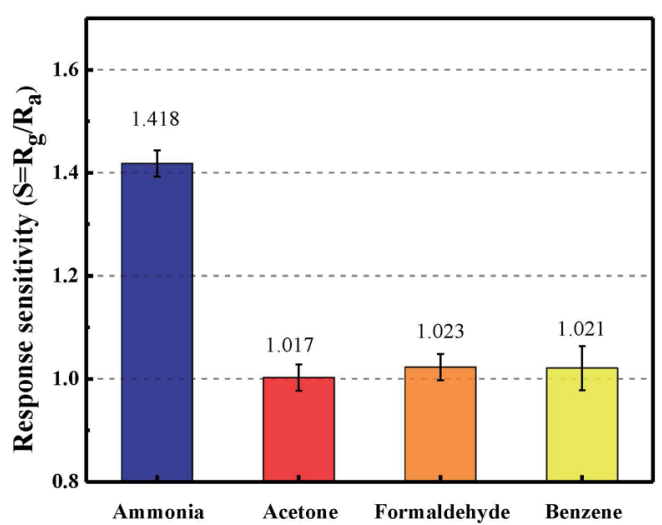

(a)

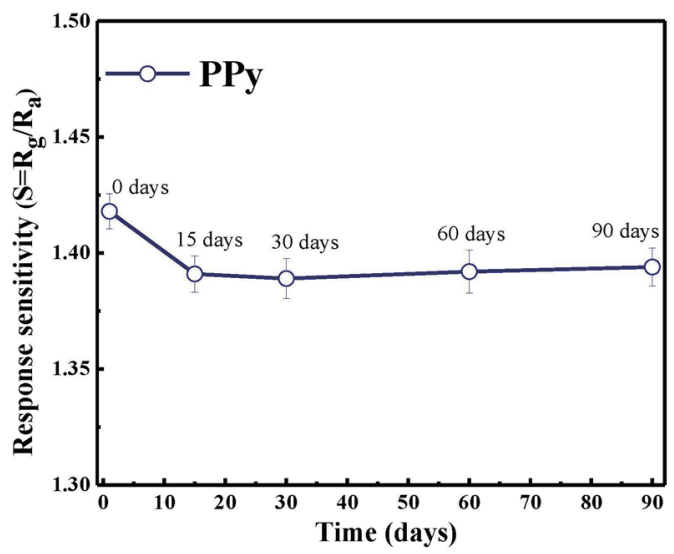

(b)

Fig. 6. (Color online) (a) Cross-responses of the PPy sensor to ammonia, acetone, formaldehyde, and benzene with a concentration of $100 \mathrm{ppm}$ at RT. (b) Long-term stability of the PPy sensor to $100 \mathrm{ppm}$ ammonia over three months.

Table 1

Adsorption energies and structural models of $n$ PPy with adsorbed ammonia.

\begin{tabular}{|c|c|c|}
\hline Species & Adsorption energy $(|\mathrm{eV}|)$ & Structural model \\
\hline $3 \mathrm{PPy}-\mathrm{NH}_{3}$ & 0.433 & \\
\hline $4 \mathrm{PPy}-\mathrm{NH}_{3}$ & 0.439 & \\
\hline $5 \mathrm{PPy}-\mathrm{NH}_{3}$ & 0.444 & \\
\hline $6 \mathrm{PPy}-\mathrm{NH}_{3}$ & 0.448 & \\
\hline $7 \mathrm{PPy}-\mathrm{NH}_{3}$ & 0.453 & \\
\hline $\begin{array}{l}n \mathrm{PPy}-\mathrm{NH}_{3} \\
(n=+\infty)\end{array}$ & 0.479 & \\
\hline
\end{tabular}

To explore the selectivity of the organic analytes to the PPy nanosheet, the 3PPy structures with adsorbed ammonia, acetone, formaldehyde, and benzene were optimized using DFT and are shown in Fig. 7. Optimized geometric parameters, i.e., the intermolecular and intramolecular distances $\left(d_{\mathrm{H} 0-\mathrm{X}}, d_{\mathrm{H} 0-\mathrm{N} 1}\right)$, the angle of the bridge $\left(\angle \mathrm{C}_{2} \mathrm{~N}_{1} \mathrm{C}_{3}\right)$, and the dihedral angle $\left(\angle \mathrm{C}_{2} \mathrm{~N}_{1} \mathrm{C}_{3} \mathrm{C}_{4}\right)$, are listed in Table 2. The intermolecular distances $\left(d_{\mathrm{H} 0-\mathrm{X}}\right)$ show distinct 


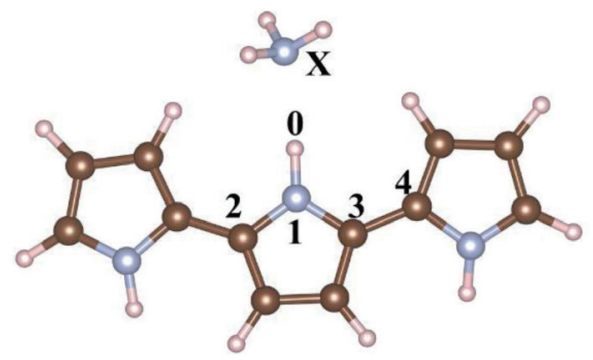

(a)

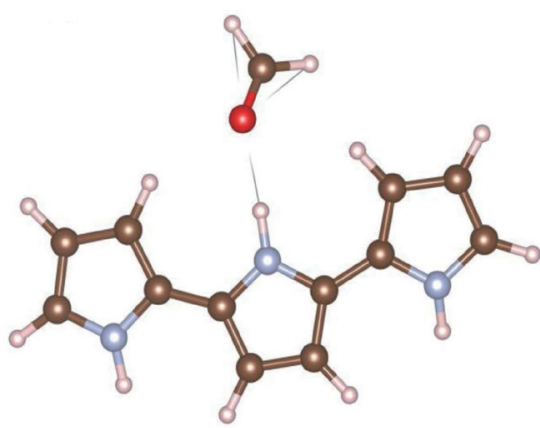

(c)

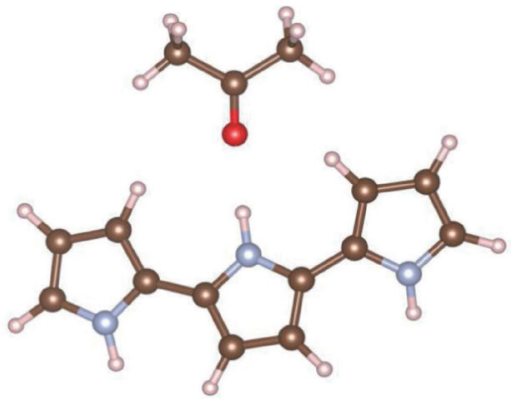

(b)

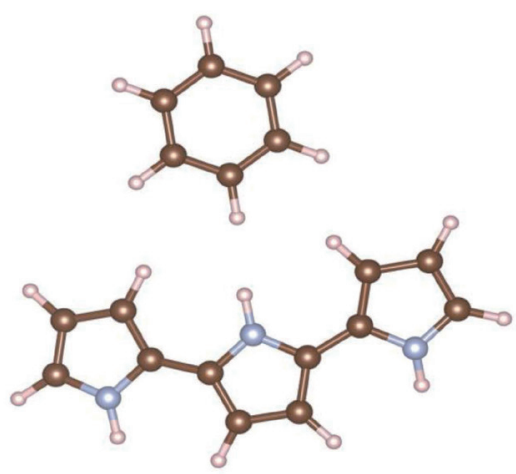

(d)

Fig. 7. (Color online) Optimized bare structure models of PPy interacting with (a) ammonia, (b) acetone, (c) formaldehyde, and (d) benzene. In (a), X denotes the nearest atom of the analyte adsorbed on the 3PPy and the atomic subscript number is shown.

Table 2

Optimized geometric parameters (bond lengths in $\AA$, bond angles in ${ }^{\circ}$ ).

\begin{tabular}{lcccc}
\hline System & $d_{\mathrm{H} 0-\mathrm{X}}$ & $d_{\mathrm{H} 0-\mathrm{N} 1}$ & $\angle \mathrm{C}_{2} \mathrm{~N}_{1} \mathrm{C}_{3}$ & $\angle \mathrm{C}_{2} \mathrm{~N}_{1} \mathrm{C}_{3} \mathrm{C}_{4}$ \\
\hline Isolated 3PPy & - & 1.017 & 110.656 & 157.294 \\
\hline 3PPy- $\mathrm{NH}_{3}$ & 1.938 & 1.034 & 110.014 & 158.162 \\
\hline 3PPy- $\mathrm{CH}_{3} \mathrm{COCH}_{3}$ & 2.456 & 1.028 & 110.456 & 156.663 \\
\hline 3PPy-HCHO & 2.489 & 1.022 & 110.187 & 157.225 \\
\hline 3PPy- $\mathrm{C}_{6} \mathrm{H}_{6}$ & 2.439 & 1.017 & 110.627 & 156.176 \\
\hline
\end{tabular}

differences with different analytes. The distance between 3PPy and ammonia of about $1.938 \AA$ was the minimum value among the four analytes, indicating the strongest interaction. The intramolecular distance $\left(d_{\mathrm{H} 0-\mathrm{N} 1}\right)$ increased with decreasing intermolecular distance $\left(d_{\mathrm{H} 0-\mathrm{X}}\right)$. Among the analytes, $d_{\mathrm{H} 0-\mathrm{N} 1}$ was largest after the adsorption of ammonia by 3PPy, which indicates that ammonia has the greatest influence on PPy nanosheets.

The bridge angle $\left(\angle \mathrm{C}_{2} \mathrm{~N}_{1} \mathrm{C}_{3}\right)$ in $3 \mathrm{PPy}$ and $3 \mathrm{PPy}-\mathrm{X}$ is another significant geometric parameter, which changed when 3PPy interacted with a gas molecule. As shown in Table 2, the maximum and minimum bridge angles were $110.627^{\circ}\left(3 \mathrm{PPy}-\mathrm{C}_{6} \mathrm{H}_{6}\right)$ and $110.014^{\circ}\left(3 \mathrm{PPy}-\mathrm{NH}_{3}\right)$, which were $0.029^{\circ}$ and $0.642^{\circ}$ less than those of the bare structure models of PPy, respectively. This also reveals that ammonia has the greatest influence on the bridge angle of PPy nanosheets. The change in the dihedral angle $\left(\angle \mathrm{C}_{2} \mathrm{~N}_{1} \mathrm{C}_{3} \mathrm{C}_{10}\right)$ was dependent on the analyte used, which was 
probably because of the ion-dipole interaction, which increased with the dihedral angle. The increase in the bridge angle led to a decrease in the resistance to electron transfer, thus enhancing the electron transfer capacity, ${ }^{(41)}$ and $3 \mathrm{PPy}-\mathrm{NH}_{3}$ also showed the largest change among the four analytes.

Simultaneously, to accurately analyze the adsorption behavior of the analytes to $3 \mathrm{PPy}$, the adsorption energies were evaluated by DFT and are shown in Table 3. The adsorption energy of ammonia adsorbed on 3PPy was about $0.433|\mathrm{eV}|$, much larger than those of acetone, formaldehyde, and benzene adsorbed on 3PPy. This illustrates that the interaction between 3PPy and ammonia was stronger than that for the other analytes. As a proof of concept, the PPy sensor showed excellent ammonia sensitivity.

The charge-density differences for 3PPy with adsorbed ammonia, acetone, formaldehyde, and benzene were investigated by QTAIM ${ }^{(31)}$ and are shown in Fig. 8. The charges transferred

Table 3

Adsorption energies and charges transferred between 3PPy and different adsorbed analytes.

\begin{tabular}{lcc}
\hline System & Adsorption energy $(|\mathrm{eV}|)$ & Charge transferred $(|\mathrm{e}|)$ \\
\hline $3 \mathrm{PPy}-\mathrm{NH}_{3}$ & 0.433 & 0.047 \\
\hline $3 \mathrm{PPy}-\mathrm{CH}_{3} \mathrm{COCH}$ & 0.254 & 0.038 \\
\hline $3 \mathrm{PPy}-\mathrm{HCHO}$ & 0.359 & 0.036 \\
\hline $3 \mathrm{PPy}-\mathrm{C}_{6} \mathrm{H}_{6}$ & 0.216 & 0.001 \\
\hline
\end{tabular}

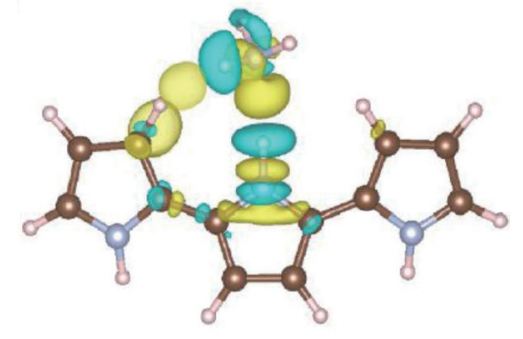

(a)

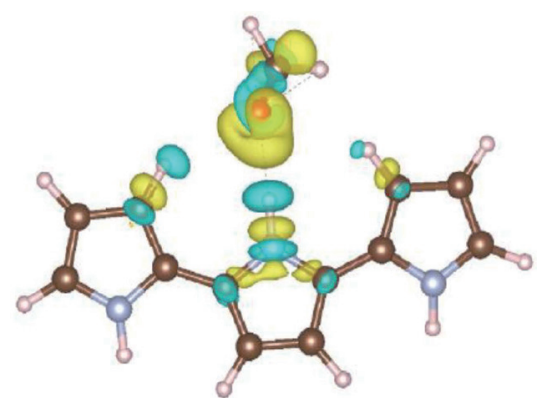

(c)

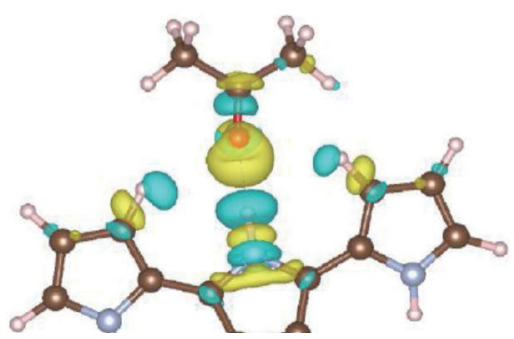

(b)

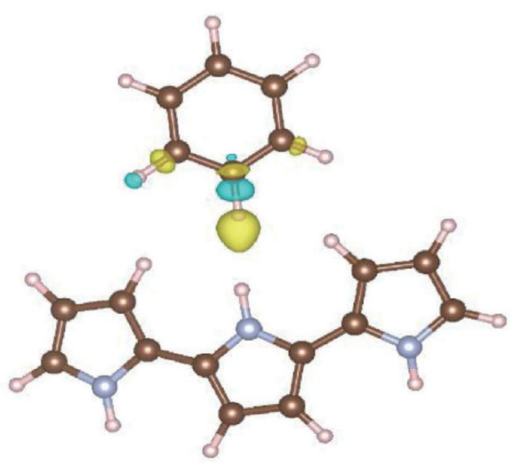

(d)

Fig. 8. (Color online) Charge-density differences for 3PPy with adsorbed (a) ammonia, (b) acetone, (c) formaldehyde, and (d) benzene. The yellow and blue regions represent increases and decreases in charge, respectively (the isosurface was set as $0.001 \mathrm{e} / \AA^{3}$ ). 
between 3PPy and different adsorbed analytes are listed in Table 3. The transferred charges between the 3PPy and ammonia, acetone, formaldehyde, and benzene molecules were $0.047|\mathrm{e}|$, $0.038|\mathrm{e}|, 0.036|\mathrm{e}|$, and $0.001|\mathrm{e}|$, respectively. The numbers of transferred charges were small between 3PPy and the analytes, which demonstrated that the interaction between 3PPy and $3 \mathrm{PPy}-\mathrm{X}$ was due to the creation/loss of ion-dipole electrostatic interactions. ${ }^{(41)}$

\section{Conclusions}

PPy was synthesized by low-temperature oxidation polymerization in a water bath at $0{ }^{\circ} \mathrm{C}$. The gas-sensing properties of a PPy sensor were measured by a dynamic test system with ammonia concentrations in the range of 2-500 ppm at RT. The PPy sensor showed excellent ammonia-sensing properties compared with acetone, formaldehyde, and benzene. It also exhibited good stability and selectivity in the presence of ammonia. The ammonia-sensing mechanism of PPy was investigated by DFT. The adsorption energy of PPy with adsorbed ammonia was larger than those of PPy with adsorbed acetone, formaldehyde, and benzene. Ammonia also had the strongest influence on the structure of PPy nanosheets, enabling gas sensing. The results suggest that the PPy sensor has promising application for the sensitive and selective detection of low concentrations of ammonia at RT. The gas sensor prepared in this work also has great potential for commercialization due to its simple preparation, excellent selectivity, low price, and RT operation.

\section{Author Contributions}

H. D. and W. Y. proposed the idea and plan of research. Z. Z. and H. D. performed the experiment and characterization. W. Y. and Z. Z. performed the DFT simulations. Y. Z. and Y. S. provided the data analysis. H. D. and Z. Z. wrote the manuscript. All authors discussed the results and contributed to the manuscript. All authors read and agreed to the published version of the manuscript.

\section{Conflicts of Interest}

The authors declare no conflicts of interest.

\section{Acknowledgments}

This research was supported in part by the National Natural Science Foundation of China under Grant Nos. 21905159, 61501081, and 61871245; the Natural Science Foundation of Liaoning Province under Grant No. 20180550624; the Ministry of Education "Chunhui Plan"; and the Natural Science Foundation of Shandong Province under Grant No. ZR2019BA010. The calculations were performed at the High Performance Computing Center (HPCC) of Qufu Normal University. 


\section{References}

1 I. P. Liu, C. H. Chang, T. C. Chou, and K. W. Lin: Sens. Actuators, B 291 (2019) 148. https://doi.org/10.1016/j. $\underline{\text { snb.2019.04.046 }}$

2 R. Farra, M. García-Melchor, M. Eichelbaum, and M. Hashagen: ACS Catalysis 3 (2013) 2256. https://doi. org/10.3390/nano9121732

3 J. Wang, X. Wei, P. Wangyang: Nanoscale Res. Lett. 10 (2015) 1. https://doi.org/10.1186/s11671-015-1170-2

4 D. Narducci: Sci. Adv. Mater. 3 (2011) 426. https://doi.org/10.1166/sam.2011.1176

5 L. G. Close, F. I. Catlin, and A. M Cohn: Arch. Otolaryngol. 106 (1980) 151. https://doi.org/ archotol.1980.00790270015004

6 C. M. Leung and C. L. Foo: Annals of the Academy of Medicine Singapore 21 (1992) 624.

7 R. E. D. L. Hoz, D. P. Schlueter, and W. N. Rom: Am. J. Ind. Med. 29 (1998) 209.

8 T. Ghafouri, R. Tahmasebi, N. Manavizadeh. Nanopart. Res. 21 (2019) 7. https://doi.org/10.1007/s11051-019$\underline{4599-\mathrm{x}}$

9 T. Ghafouri, R. Tahmasebi, and N. Manavizadeh: J. Nanopart. Res. 12 (2010) 1095. https://doi.org/10.1007/ s11051-010-9878-5

10 K. Zakrzewska: Thin Solid Films 391 (2001) 229. https://doi.org/10.1016/S0040-6090(01)00987-7

11 P. T. Moseley: Sci. Technol. 8 (1997) 223. https://doi.org/10.1088/0957-0233/8/3/003

12 A. Spetz, M. Armgarth, and I. Lundstrom: J. Appl. Phys. 64 (1988) 1274. https://doi.org/10.1063/1.341846

13 Lähdesmäki Ilkka: Talanta 53 (2000) 269. https://doi.org/10.1016/S0039-9140(00)00330-1

14 A. L. Kukla, Y. M. Shirshov, and S. A. Piletsky: Sens. Actuators, B 37 (1996) 135. https://doi.org/10.1016/ S0925-4005(97)80128-1

15 N. R. Tanguy, M. Arjmand, and N. Yan: Adv. Mater. Interfaces 6 (2019) 1900552. https://doi.org/10.1002/ admi.201970101

16 R. Ramya, R. Sivasubramanian, and M. V . Sangaranarayanan: Electrochimica Acta. 101 (2013) 109. https:// doi.org/10.1016/j.electacta.2012.09.116

17 X. Yuan, X. L. Ding, and C. Y. Wang: Energy Environ. Sci. 6 (2013) 1105. https://doi.org/10.1039/C3EE23520C

18 B. M. Lee, J. E. Kim, F. F. Fang, and H. J. Choi: Macromol. Chem. Phys. 212 (2011) 2300. https://doi. org/10.1002/macp.201100306

19 H. D. Tran, L. Dan, and R. B. Kaner: Adv. Mater. 21 (2009) 1487. https://doi.org/10.1002/adma.200802289

20 G. D, Khuspe and D. K. Bandgar: Synth. Met. 162 (2012) 1822. https://doi.org/10.1016/j.synthmet.2012.08.022

21 J. Bobacka, A. Ivaska, and A. Lewenstam Chem. Rev. 108 (2008) 329. https://doi.org/10.1021/cr068100w

22 A. Joshi, S. A. Gangal, and S. K. Gupta: Sens. Actuators, B 156 (2011) 938. https://doi.org/10.1016/j. snb.2011.03.009

23 M. Penza, E. Milella,and M. B. Alba: Sens. Actuators, B 40 (1997) 205. https://doi.org/10.1016/S09254005(97)80263-8

24 D. U. Kim and B. Yoo: Sens. Actuators, B 160 (2011) 1168. https://doi.org/10.1016/j.snb.2011.09.042

25 A. Joshi, S. A. Gangal, and S. K. Gupta: Sens. Actuators, B 156 (2011) 938. https://doi.org/10.1016/j. snb.2011.03.009

26 H. Du, J. Wang, and Y. Sun: Sens. Actuators, B 206 (2015) 753. https://doi.org/10.1016/j.snb.2014.09.010

27 G. Kresse and J. Furthmüller: Phys. Rev. B 54 (1996) 11169. https://doi.org/10.1103/PhysRevB.54.11169

28 J. P. Perdew, K. Burke, and M. Ernzerhof: Phys. Rev. Lett. 77 (1996) 3865. https://doi.org/10.1063/1.472933

29 J. Klimes, D. Bowler, and A. Michaelides: 2011 APS March Meeting. B 83, 195131 1-13.

30 H. Du, W. Yang, and W. Yi: ACS Appl. Mater. Interfaces 12 (2020) 23084. https://doi.org/10.1021/ acsami.0c03498

31 W. Tang, E. Sanville, and G. Henkelman: J. Phys. Condens. Matter 21 (2009) 84204-0. https://doi. org/10.1088/0953-8984/21/8/084204

32 W. Yi, G. Tang, and X. Chen: Comput. Phys. Commun. 257 (2020) 107535. https://doi.org/10.1016/j. cpc. 2020.107535

33 S. C. Hernandez, D. Chaudhuri, and W. Chen: Electroanalysis 19 (2007) 2125. https://doi.org/10.1002/ elan.200703933

34 A. T. Mane, S. D. Sartale, and V . B. Patil: J. Mater. Sci. 26 (2015) 8497. https://doi.org/10.1007/s10854-015$\underline{3521-2}$

35 J. Sun, X. Shu, Y. Tian, and Z. Tong: Sens. Actuators, B 241 (2017) 658. https://doi.org/10.1016/j.snb.2016.10.047

36 B. Ruan, H. Guo, and Q. Liu: RSC Adv. 6 (2016) 103124. https://doi.org/10.1039/C6RA21139A

37 A. Beniwal and Sunny: Sens Actuators, B 296 (2019) 126660. https://doi.org/10.1016/j.snb.2019.126660

38 F. Li, H. Li, H. Jiang, and K. Zhang: Appl. Surf. Sci. 280 (2013) 212. https://doi.org/10.1016/j.apsusc.2013.04.132 
39 L. Jiwei, Q. Jingxia, Y. Miao, and J. Chen: J. Mater. Sci. 43 (2008) 6285. https://doi.org/10.1007/s10853-0082905-6

40 S. Bibi, H. Ullah, and S. M. Ahmad: J. Phys. Chem. C 119 (2015) 15994. https://doi.org/10.1021/acs. jpcc. 5 b03242

41 A. S. Rad, N. Nasimi, and M. Jafari: Sens. Actuators, B 220 (2015) 641. https://doi.org/10.1016/j.snb.2015.06.019 